[Radiocarbon, Vol 22, No. 3, 1980, P 695-704]

\title{
HOLOCENE SEA-LEVEL HISTORY: CASE STUDY OF THE STATISTICAL EVALUATION OF ${ }^{14}$ C DATES
}

\author{
MEBUS A GEYH \\ Niedersächsisches Landesamt für Bodenforschung, \\ D3000 Hannover, Germany
}

ABSTRACT. The limits of the statistical evaluation of ${ }^{14} \mathrm{C}$ dates by histograms are discussed. The method of the attempt to establish a global chronology of the shortterm eustatic sea-level changes during the Holocene is examined as well as its correlation with the precisely determined Suess wiggles.

\section{INTRODUCTION}

An increase in global temperature causes melting of the ice caps on the poles and innundation coastal areas, which are the most productive for agriculture. In the near future such a change of climate could be forced by the rise in the atmospheric $\mathrm{CO}_{2}$ content due to energy production from fossil hydrocarbons and coal. In order to understand if shortterm sea-level changes of relatively small amplitude have been a global phenomenon and which natural forces could be responsible, the study of this subject has become a leading project in the International Geological Correlation Programmes. The knowledge of a reliable chronology of eustatic sea-level variations would help decide the more valuable of the two existing conceptions. Sheppard and Curray (1967) have assumed a smooth increase of the sea level during the Holocene while Fairbridge and Hillaire-Marcel (1977) have constructed an undulating sea-level curve with amplitudes of a few meters.

In order to recognize globally or even regionally coinciding periods of approximately 100 years duration or less, which may be characteristic for the Holocene sea-level changes, the statistical evaluation of ${ }^{14} \mathrm{C}$ dates by histograms appeared to be better than the interpretation of individual ${ }^{14} \mathrm{C}$ dates. However, there are fundamental limits of this method which are discussed in this paper.

\section{Statistical evaluation of ${ }^{14} \mathrm{C}$ dates by histograms}

The statistical evaluation of ${ }^{14} \mathrm{C}$ dates by histograms has been applied in studies of the Holocene sea-level changes (Geyh, 1969; Geyh and Streif, 1970; Geyh, 1971; Andrews and others, 1972; Shennan, 1978), the global climate during the Late Pleistocene (Geyh and Rohde, 1972) and for the climate (Geyh and Jäkel, 1977) and the paleohydrogeology of the Sahara desert (Sonntag and others, 1978).

The radiometric dates with their standard deviations represent Gaussian frequency distributions that may be approximated by simple rectangles or polynoms (fig 1). As the areas under any of these geometric forms are made of the same size, the standard deviation $\sigma$ determines the height of the geometric form selected. The larger the standard deviation, the lower the height of the figure.

Histograms are superpositions of such areas, each belonging to one date (fig 2). Hence, the heights of peaks cannot be interpreted quantita- 
tively if the set of dates has greatly differing standard deviations. As shown, the shape of the histogram is not noticeably influenced by the geometric form selected. We use polynoms.

The basic assumptions of the histogram evaluation of ${ }^{14} \mathrm{C}$ dates are as follows:

- The frequency distribution of the dated samples represents their actual occurrence in the area and the time range under investigation. This assumption is rather well fulfilled if there is a great number of sample submitters. There is no over- or under-representation due to the accessibility of samples or their preferred collection in respect to certain objects of interest. This assumption has to be checked separately. For instance, it is customary to take base and top of datable deposits in coastal peat beds because doubling of histogram peaks would be expected. However, the couples of dates are shown as a joint peak because their standard deviations have a size similar to the durations of the transgressions or regressions, respectively.

- Dislocated or contaminated samples are seldom over the time range of investigation. Contaminations exceeding 5 percent are exceptions and are randomly distributed. ments:

The interpretation of ${ }^{14} \mathrm{C}$ histograms is based on the following state-

- The time range of the peaks correspond to periods of preferred occurrence of the dated substances as periods of groundwater recharge,

\section{FORMS OF GRAPHICAL REPRESENTATION OF THE GAUSSIAN FREQUENCY DISTRIBUTION}

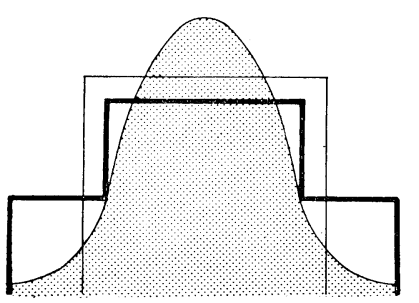

$A \pm 26$

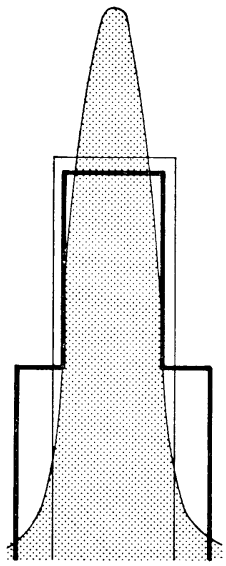

$B \pm \sigma$
Fig 1. Three forms for the graphic presentation of radiometric dates with different standard deviations $\sigma(\sigma \mathrm{A}=2 \cdot \sigma \mathrm{B})$. Usually, the width of the rectangles is chosen to be $2 \sigma$. Exceptionally, we used a slightly greater value in order to distinguish the different shapes well.

\section{CONSTRUCTION OF A HISTOGRAM FROM 5 DATES}
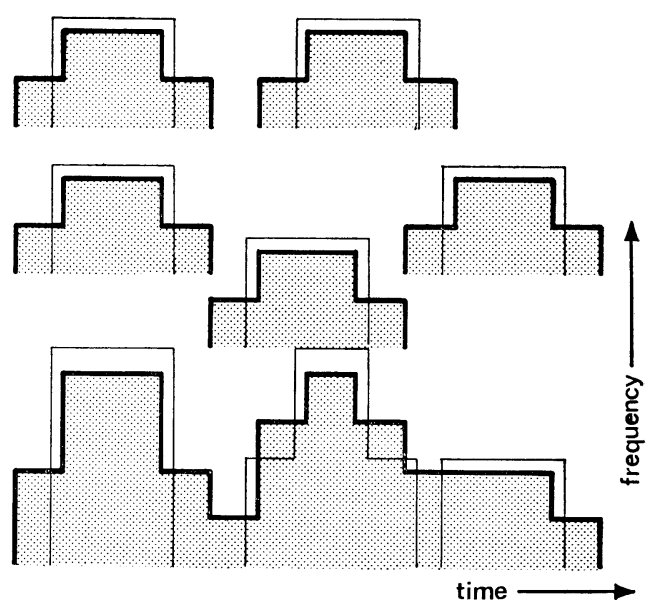

Fig 2. Construction of a histogram by superpositioning of 5 areas each belonging to one date. Two geometric forms for the representation of the dates are used. 
growth of trees and peat and the development of settlements. Apparently, convincing results obtained by the above cited statistical investigations support that this statement usually seems to be fulfilled.

- Time ranges of both peaks and gaps are accepted to be real if they coincide with those of other histograms constructed from dates of adjacent regions of similar history or of other substances. The time ranges of coinciding peaks are minimum values; those of corresponding gaps are maximum values.

- The shape of the histograms is not truncated as the result of a divergence between the siderical and the radiometric time scales (Geyh and Streif, 1970; Geyh, 1971). This appears to be the most serious point.

\section{Conception of the histogram evaluation}

The theoretical background of the histogram evaluation was first touched by Shennan (1978) who constructed them using computer generated random numbers instead of ${ }^{14} \mathrm{C}$ dates. His histograms show similar frequent peaks as real ${ }^{14} \mathrm{C}$ histograms although the same number of dates was used. This result makes it necessary to consider the statistical background in more detail.

1) Number of dates and size of standard deviation. The time range $\mathrm{T}$ of a histogram can be divided in so-called class intervals, whose width may be defined as twice the standard deviation $\sigma$ of the dates. Random numbers are uniformly distributed over all class intervals and the columns above each class interval should have the same height. However, the probability that an individual date belongs to a certain class interval is described by Poisson statistics. Accordingly, the columns show statistically determined differences of the heights which are a function of the population density $\mathrm{z}$ (number of random numbers [dates] per class interval). The relative statistical fluctuations $\mathrm{s}$ are given by

$$
\mathrm{s}= \pm 1 / \sqrt{\mathrm{z}}= \pm \sqrt{\mathrm{T} /(2 \cdot \mathrm{Z} \cdot \sigma)}
$$

where $\mathrm{Z}$ is the number of random numbers within the time range $\mathrm{T}$.

The relationship between s, $\sigma$ and $\mathrm{Z}$ is demonstrated by 3 histograms (fig 3). In these examples, the calculated statistical fluctuations are \pm 30 percent according to a population density of 10.8 random numbers per class interval. Then, one statistically created gap below 60 percent of the mean height must be expected within 20 class intervals. If the population density is only 4 random numbers (dates) per class interval, a statistically created gap within 3 class intervals reaching the base line is present. As seen in figure 3, real gaps of one class interval can only be recognized reliably if the statistical fluctuations are smaller than \pm 20 percent. If $\mathrm{s}$ is greater because $\mathrm{Z}$ is too small, a few histograms of the same chronology but of different origin (region or substance) have been placed together (fig 3).

The calculation of floating means by combining dates (random numbers) of adjacent class intervals will not help to overcome the problem of insufficient dates. Both real and statistical gaps will be smoothed out in the same manner and finally disappear. 


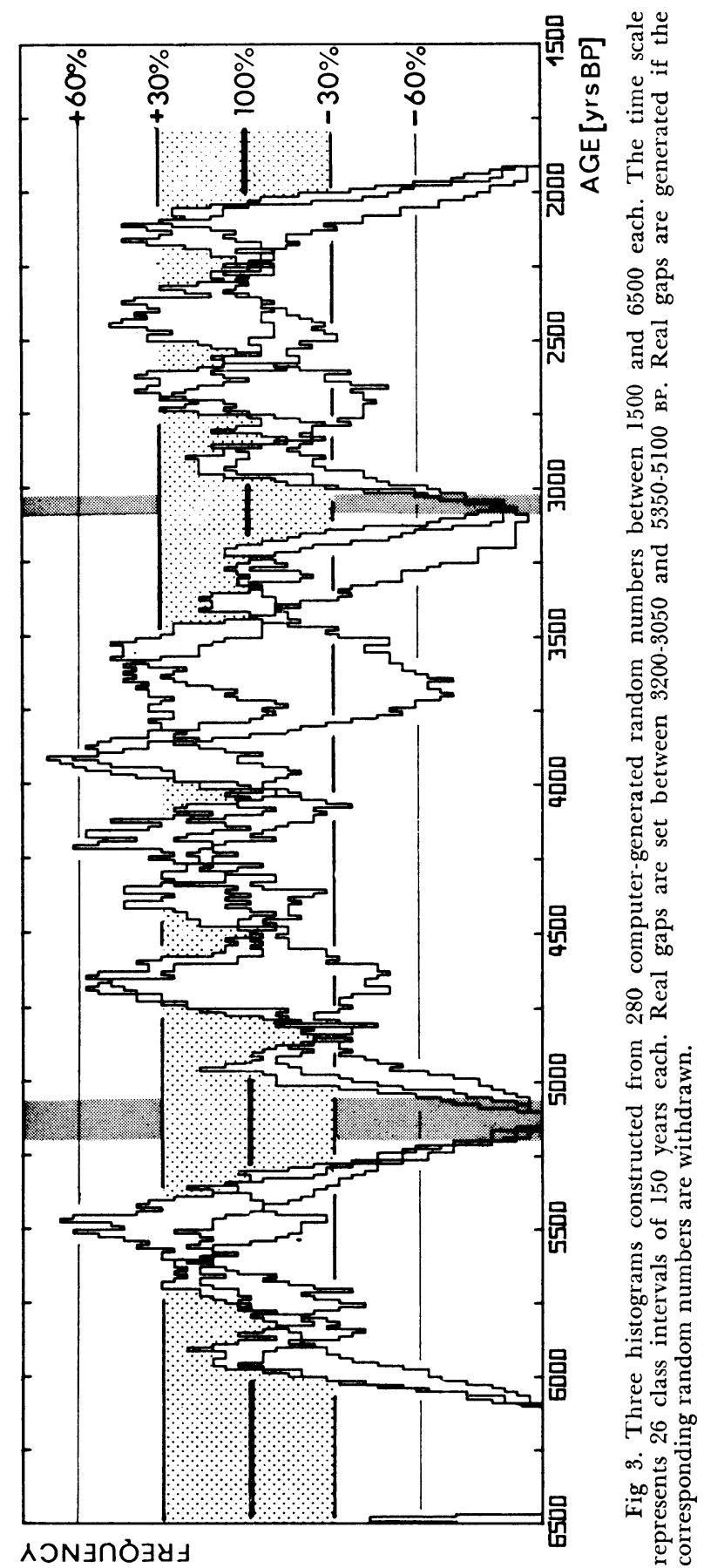


2) Contamination of samples. Two histograms were constructed from the same set of random numbers (fig 4). However, the random numbers of one of them were recalculated assuming that 30 percent are diminished due to 10 percent contamination with recent carbon. Although this assumption is worse than the conditions present in nature, both histograms have comparable shapes and only an unimportant shift of the peaks is visible.

3) Conclusions. With respect to the statistics, three kinds of histograms are distinguished:

- Reliable histograms are constructed from at least 25 dates per class interval of two standard deviations. Real gaps with a width of at least one class interval can be reliably recognized.

- Common histograms have population densities between 4 and 25 dates per class interval, and

- Unreliable histograms have a population density of less than 4 dates per class interval. Real gaps are recognized by placing together a few histograms of the same chronology (fig 3). These gaps should be directly related to geologic events and, therefore, allow a definite conclusion. But neither the actual presence nor its potential for occurrence of datable material during a specific time in the past will necessarily show up as a peak in the histogram.

With this classification in mind, events can be studied by the histogram presentation of dates that lasted at least one class interval and were characterized by a lack of datable material.

\section{Chronology of sea-level changes}

The morphology of rising shores as in Canada (Fairbridge and Hillaire-Marcel, 1977) and Scandinavia (Mörner, 1976) provides evidence for periods of sea-level standstill or slowly rising sea level. The same

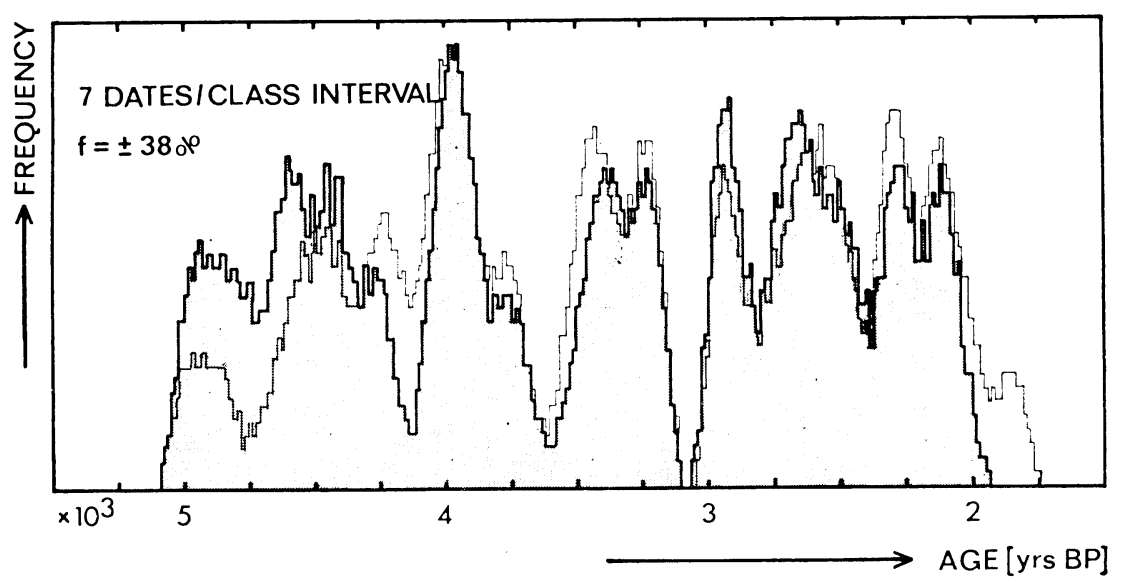

Fig 4. Two histograms between 5000 and 2000 BP constructed from the same set of 210 random numbers. The random numbers of one set (thin line) were recalculated assuming that 30 percent are diminished due to 10 percent contamination with recent carbon. The width of the class interval is 100 years. 
events are reflected as intercalated phragmitic peat beds in sediments of subsiding shores as on the North Sea (Jelgersma, 1961). Periods of transgressions are manifested by silt and clay beds. As sediment cores from different locations seem to reflect only local sea-level events, the question arose if temporally coinciding transgressions have occurred all over the world.

We constructed histograms from ${ }^{14} \mathrm{C}$ dates of samples taken from intercalated phragmitic peat beds (without basal peat) for restricted parts of the North Sea (Schleswig-Holstein, East Friesland, Jade Bay, Elbe River region, Hadern) and placed them together with those for the Netherlands (Jelgersma, 1961), England (Tooley, 1978), Sweden (Mörner, 1976) and Australia (Thom and others, 1978). Different regions were studied separately in order to determine whether regional or local events have been dominant. The simplified histograms are shown in figure 5. Each region shows an individual gap and peak distribution and the histograms are not comparable with each other as are the sediment profiles. The differing shapes may be partly due to statistical fluctuations but mainly reflect an individual local development of the peat and clay layers. However, there are also gaps synchronous in all histograms, although dates from different laboratories, three decades and various substances were used. These gaps were considered to represent periods of global transgressions which apparently seldom lasted longer than 100 years. Of course, gaps might have been smoothed out by ${ }^{14} \mathrm{C}$ dates of contaminated samples or by differences of the time scales of the ${ }^{14} \mathrm{C}$ laboratories. This sea-level chronology (table 1) rather completely overtaken by Fairbridge and Hillaire (1977) agrees so well with those derived by classic geologic methods that the occurrence of world-wide synchronous eustatic transgressions during the Holocene was considered certain.

With this in mind, the sea-level chronology was compared with the preliminary ${ }^{14} \mathrm{C}$ correction curve which represents the global atmosphere

TABLe 1

Duration (yr BP) of gaps ( $\geqslant 50 \mathrm{yr}$ ) of the global ${ }^{14} \mathrm{C}$ histogram in comparison to geologically derived chronologies of transgressions.

\begin{tabular}{ccccc}
\hline $\begin{array}{c}\text { Global } \\
\left(\begin{array}{c}\text { Geyh } \\
1980\end{array}\right)\end{array}$ & $\left.\begin{array}{c}\text { England } \\
\text { Tooley } \\
1978\end{array}\right)$ & $\left.\begin{array}{c}\text { South America } \\
\text { Fairbridge and } \\
\text { Hillaire-Marcel } \\
1977\end{array}\right)$ & $\left.\begin{array}{c}\text { Sweden } \\
\text { Mörner } \\
1976\end{array}\right)$ & $\left.\begin{array}{c}\text { North Sea Coast } \\
\text { Geyh and Streif } \\
1971\end{array}\right)$ \\
\hline $6700-6600$ & $6710-$ & $6800-6700$ & & 6750 \\
$6400-6300$ & -6160 & $6350-6300$ & $6450-6200$ & 6320 \\
$5875-5825$ & $5950-5775$ & $6100-5900$ & $5900-$ & $5950-$ \\
$5550-5450$ & $5570-$ & $5600-5500$ & -5500 & -5550 \\
$5100-5050$ & -4900 & $5100-5000$ & $5000-$ & 5050 \\
$4600-4500$ & & $4700-4550$ & -4550 & 4540 \\
$3975-3925$ & $4150-4000$ & $4300-3950$ & $4250 / 3870$ \\
$3650-3600$ & $3700-3150$ & $3850-3620$ & $3600-3200$ & 3450 \\
$2850-2775$ & $3090-$ & $3000-2800$ & & 2820 \\
$2625-2575$ & & $2600-2550$ & $2700-$ & 2560 \\
$2400-2350$ & -2270 & $2400-2200$ & -2400 & 2350 \\
$2025-1950$ & $1800-1370$ & $1850-1600$ & $1800-1300$ & 2160 ? \\
$1750-1700$ & 1700
\end{tabular}




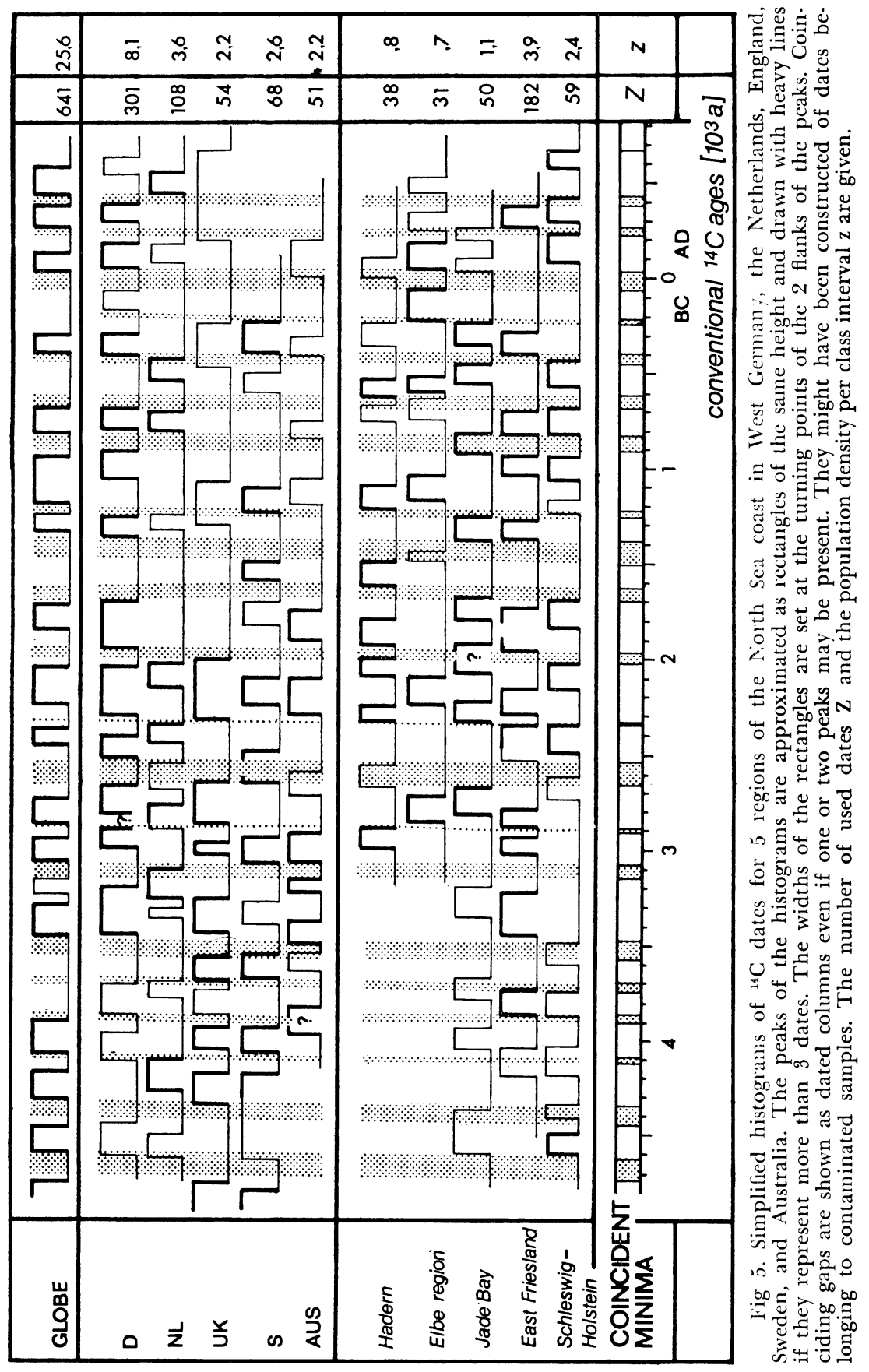




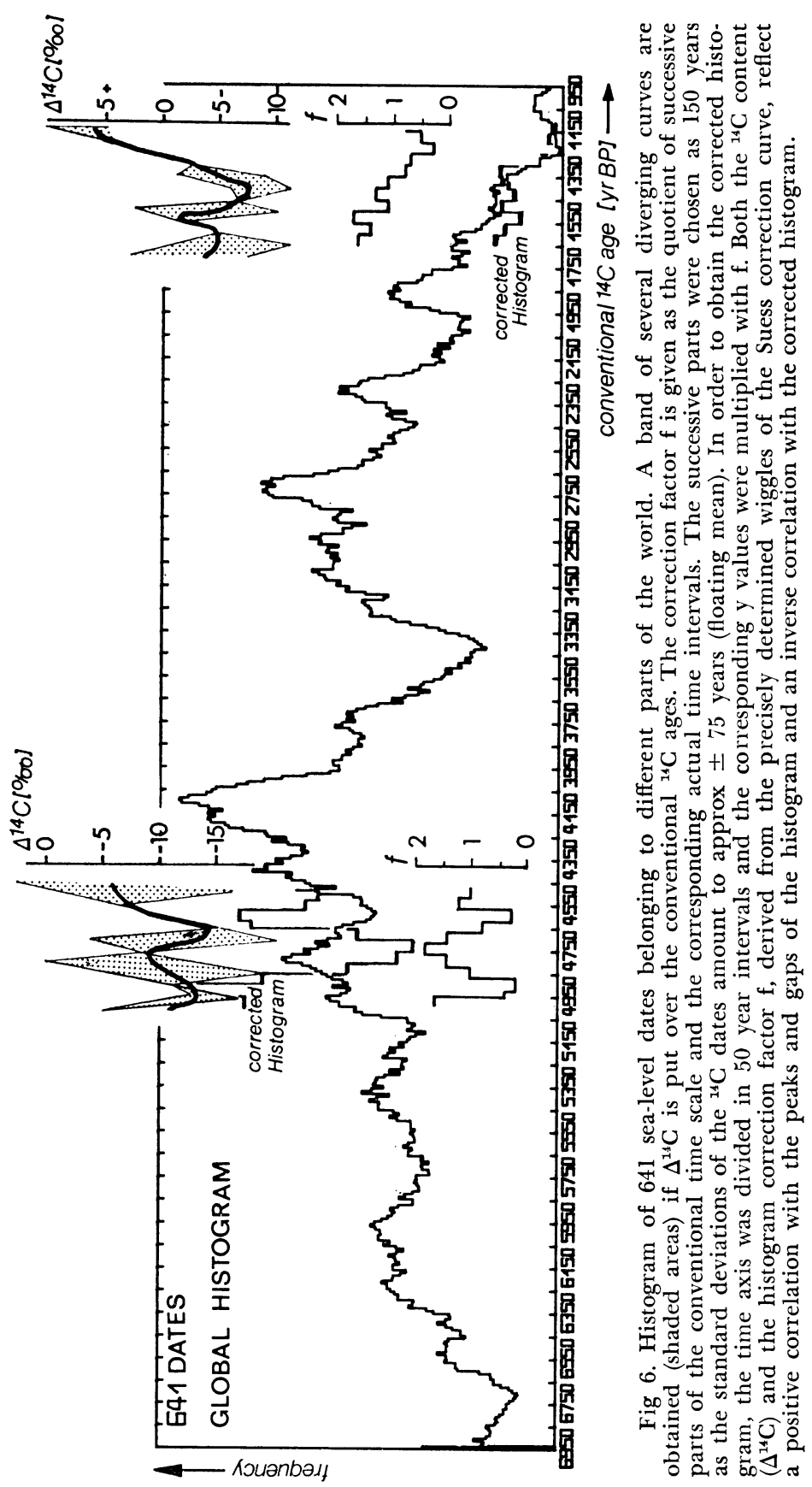


(Geyh, 1971). However, first the precisely determined Suess wiggles (de Jong, Mook, and Becker, 1979; Bruns, Münnich, and Becker, 1980) allow an attempt at reliable correlation (fig 6). The peaks of the histogram coincide with those of the ${ }^{14} \mathrm{C}$ content $\left(\Delta^{14} \mathrm{C}\right)$; the histogram corrected for the distortion of the ${ }^{14} \mathrm{C}$ time scale (Geyh, 1971) shows peaks instead of gaps of the uncorrected histogram and vice versa; the course of the histogram correction factor $\mathrm{f}$ (floating mean of 150 years) is similar to that of the uncorrected histogram.

These observations offer two alternative conclusions:

1) The shape of the histogram does exclusively reflect the distortion of the ${ }^{14} \mathrm{C}$ time scale by the ${ }^{14} \mathrm{C}$ wiggles (Stuiver, 1969). If globally coinciding sea-level changes should have existed, their durations were too short to become visible in the histogram.

2) The shape of the histogram reflects both the distortion of the ${ }^{14} \mathrm{C}$ time scale and global sea-level changes. (This conclusion may be supported by the finding that the histogram cannot be smoothed out by the correction). Then, both effects are coincident and must have been caused by the same natural force. A high ${ }^{14} \mathrm{C}$ activity coincides with periods of low peat occurrence or transgressions which account for relative high global temperature. This would be in agreement with the positive correction between ${ }^{14} \mathrm{C}$ content and tree-ring growth (Bruns, Münnich, and Becker, 1980). It contradicts, however, former correlations with sun spot numbers if no phase shift between these effects should exist.

Apart from these controversies, histogram evaluation of ${ }^{14} \mathrm{C}$ dates allows a reliable recognition of long-term periods without sample occurrence (eg, glacial periods or phases of drought). When short-term processes are studied, statistically created undulations of the histogram as well as distortion of the ${ }^{14} \mathrm{C}$ time scale become dominant and may mask the object under investigation.

In respect to short-term sea-level changes, the histogram evaluation does not yet allow a final conclusion about their global occurrence. However, the ${ }^{14} \mathrm{C}$ correction curve, once determined with high precision, may contribute to solving the problem of global sea-level changes and to define the limits of the histogram evaluation of ${ }^{14} \mathrm{C}$ dates.

\section{REFERENCES}

Andrews, J T, Mears, A, Miller, G H, and Pleasant, D R, 1972, Holocene Late Glacial maximum and marine transgressions in the eastern Canadian Arctic: Nature, Phys Sci, v 239, p 147-149.

Bruns, Michael, Münnich, K O, and Becker, Bernd, 1980, Natural radiocarbon variations from AD 200 to 800 , in Stuiver, Minze and Kra, Renee, eds, Internatl radiocarbon conf, 10th, Proc: Radiocarbon, v 22, no. 2, p 273-278.

Fairbridge, R W and Hillaire-Marcel, C, 1977, An 8000 year palaeoclimatic record of the 'Double-Hale' 45 year solar cycle: Nature, v 268, no. 5619, p 413-416.

Geyh, M A, 1969, Versuch einer chronologischen Gliederung des marinen Holozäns an der Nordseeküste mit Hilfe der statistischen Auswertung von ${ }^{14} \mathrm{C}$-Daten: Deutsche geol Gesell Zeitschr, v 118, p 351-360.

1971, Middle and young Holocene sea-level changes as global contemporary events: Geol fören Stockholm Förh, v 93, p 679-691.

Geyh, M A and Jäkel, D, 1977, The climate of the Sahara during the Late Pleistocene and the Holocene on the basis of available radiocarbon dates: Natl Resources and Development, v 6, p 64-79. 
Geyh, M A and Rohde, P, 1972, Weichselian chronostratigraphy, ${ }^{14} \mathrm{C}$ dating and statistics, in Internatl geol cong, 24th, Proc: Montreal, sec 12, p 27-36.

Geyh, M A and Streif, J, 1970, Studies on coastal movements and sea-level changes by means of the statistical evaluation of ${ }^{14} \mathrm{C}$ data, in Internatl symposium coastal geodesy, Proc: Munnich, p 599-611.

Jelgersma, S, 1961, Holocene sea-level changes in the Netherlands: Geol Stichting Med, v C VI 7, p 1-100.

de Jong, A F M, Mook, W G, and Becker, Bernd, 1979, Confirmation of Suess wiggles: 3200-3700 BC: Nature, v 280, no. 5717, p 48-49.

Mörner, N-A, 1976, Eustatic changes during the last 8000 years in view of radiocarbon calibration and new information from the Kattegatt region and other northwestern European areas: Palaeogeog, Palaeoclimatol, Palaeoecol, v 19, p 63-85.

Shennan, I, 1978, Statistical evaluation of sea-level data, in Tooley, M, ed, IGCP Proj 61, Sea-level changes, Bull: Durham.

Sheppard, F P and Curray, J R, 1967, Carbon-14 determination of sea-level changes in stable areas: Progress in Oceanography, volume 4: Oxford, Pergamon Press, p 283-291.

Sonntag, C, Klitzsch, E, El Shazley, E M, Kalinke, C and Münnich, K O, 1978, Paläoklimatische information im Isotopengehalt ${ }^{14} \mathrm{C}$ datierter Saharawässer: Kontinentaleffekt in D und ${ }^{18} \mathrm{O}$ : Geol Rundshau, v 67, p 413-424.

Stuiver, Minze, 1969, Evidences for the variation of atmospheric ${ }^{14} \mathrm{C}$ content in the Late Quaternary, in Turekian, K K, ed, Late Cenozoic glacial ages: New Haven, Yale Univ Press, p 57-70.

Tooley, M J, 1978, Sea-level changes during the Flandrian stage: Oxford, Clarendon Press, p 232.

\section{DISCUSSION}

Mook: I would like to comment on the essence of the histogram. If peat is properly collected for ${ }^{14} \mathrm{C}$ dating, samples are dated from the base as well as from the top of the peat layers. At least in my country this is always being done. This means, however, 1) that the number of peaks in a total histogram is twice the number of actual peat layers, 2) the distribution of ${ }^{14} \mathrm{C}$ dates in time is not random, but very well selected. Therefore, the peaks in the histogram are not caused by the natural ${ }^{14} \mathrm{C}$ variations (Suess wiggles) but deliberately by man collecting the samples and by the events causing the peat layers.

Geyh: 1) Double peaks do not appear in histograms as samples taken from the top and base of the same peat layer at different distances from the base will cover the whole period suitable for peat growth. In addition, the time resolution of \pm 100 years is too long for recognizing shortterm periods. 2) As we have not interpreted peaks, but gaps, we hope to overcome the difficulty arising from non-randomly distributed dates. However, it remains a surprising finding that the maximum of the ${ }^{14} \mathrm{C}$ content in atmospheric $\mathrm{CO}_{2}$ coincide with the peaks in the histograms. Our explanation is that both ${ }^{14} \mathrm{C}$ production and sea-level changes are directed by the same natural forces.

Silar: Have you distinguished between tectonic events and eustatic oscillation of the sea level when analyzing the present position of the ${ }^{14} \mathrm{C}$ samples?

Geyh: Unfortunately, it is not yet possible to distinguish between these two effects. However, in our study it was only necessary to find indications for relations to sea-level changes which was always guaranteed by the submitting geologists. 